\title{
Criticisms and Controversies in the Diagnosis of Cheilitis ${ }^{+}$
}

\author{
Umberto Romeo*, Federica Rocchetti and Alessandra Montori \\ Department of Oral and Maxillo-Facial Sciences, Sapienza University of Rome, 00161 Rome, Italy; \\ federica.rocchetti@uniroma1.it (F.R.); montorialessandra@gmail.com (A.M.) \\ * Correspondence: umberto.romeo@uniroma1.it; Tel.: +393334134697 \\ + Presented at the XV National and III International Congress of the Italian Society of Oral Pathology and \\ Medicine (SIPMO), Bari, Italy, 17-19 October 2019.
}

Published: 11 December 2019

The term "cheilitis" refers to an inflammatory condition of the lip and encompasses an heterogeneous group of lesions of different etiology, clinical aspects, management and prognosis [1].

The lips cosmetically characterize the face of a person; they are fundamental to speach, eat and acting as a tattile organ. For such reasons, even a little alterations of the anatomy or functionality, are experienced by the patient with a certain discomfort and embarrassment.

Althought cheilitis has been identified and recognized for a long time, until now there have been confusion among clinicians due to poor knowledge, use of improper terminology, no clear recommendations for its work-up and classification [2].

Literature reports many papers on cheilitis but they are mostly case reports and overviews of therapeutic or diagnostic procedures based on personal experiences and results without specific criteria for classification.

In fact, about 30 articles were identified, performing a research using MEDLINE/PubMed and Cochrane Library databases with the keywords "cheilitis, lip cheilitis, lip inflammation, classification" and the Boolean operators "AND" and "OR" in order to combine the keywords,

Apart from that, some types of cheilitis requires a multidisciplinary approach between oral pathologists, dermatologists, otorhinolaryngologists, which additionally complicates adoption of a classification system.

According to our opinion, the classification proposed by Lugovic-Mihic et al. based on the duration and etiology of cheilitis is useful, but should be integrate with some forms of cheilitis in order to guarantee simplification of the diagnosis, appropriate treatment and benefits for patients.

The classification is shown in Table 1.

Table 1. Lugović-Mihić et al. modified classification of cheilitis.

\begin{tabular}{|c|c|c|}
\hline Mostly Reversible & Mostly Persistent & $\begin{array}{c}\text { In Association with Dermatosis and } \\
\text { Systemic Deseases (Common Deseases) }\end{array}$ \\
\hline 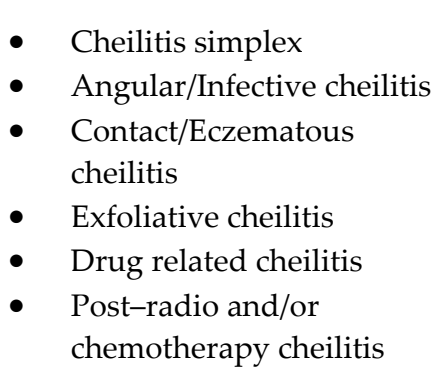 & $\begin{array}{l}\text { - } \text { Actinic cheilitis } \\
\text { - } \text { Granulomatous } \\
\text { cheilitis } \\
\text { - Glandular } \\
\text { cheilitis } \\
\text { - } \begin{array}{l}\text { Plasma cell } \\
\text { cheilitis }\end{array}\end{array}$ & $\begin{array}{ll}\text { - } & \text { Lupus erythematosus } \\
\text { - } & \text { Lichen Planus } \\
\text { - } & \text { Angioedema } \\
\text { - } & \text { Pemphigus/Pemphigoid } \\
\text { - } & \text { Xerostomia } \\
\text { - } & \text { Erythema multiforme } \\
\text { - } & \text { Crohn's desease } \\
\text { - } & \text { Sarcoidosis } \\
\text { - } & \text { Psoriasis, etc. }\end{array}$ \\
\hline
\end{tabular}


Mostly reversible and irreversible cheilitis are competence of stomatologists; instead, for the cheilits connected to dermatoses and systemic diseases the multidisciplinary care is mandatory.

Cheilitis of more clinical interest will be treated below.

Cheilitis simplex is one of the most common types and presents as cracked, fissured, desquamated lips. Frequent lip licking or sucking promote dryness and irritation, ending in separation of the mucosa and cracking. Therapy mostly involves advice on dealing with environmental conditions, application of lip balms and sometimes topical corticosteroids.

Angular cheilitis, also called perlèche, typically manifests at the corners of the mouth. Vitamin and mineral deficiencies (B vitamins, iron, zinc, etc.), the loss of skin turgor due to aging, the loss of vertical dimension of the face due to severe edentulous states, retrognathic malocclusion are the most frequent causes [3]. Concurrence of bacterial (staphylococcal and betahemolytic streptococcal) or candidal infectionsis common. Therapy includes elimination of predisposing factors and often topical antimycotics, antiseptics and sometimes corticosteroids.

Contact cheilitis (Figure 1) is caused by the irritating or allergic effects of various substances found in many products such as lipsticks, oral hygiene products (toothpastes), food (e.g., eggs and crustaceans), spices or flavouring agents and dental materials [4]. Patch tests can play a pivotal role in the diagnosis, although its diagnostic use is still controversial in the literature [5].

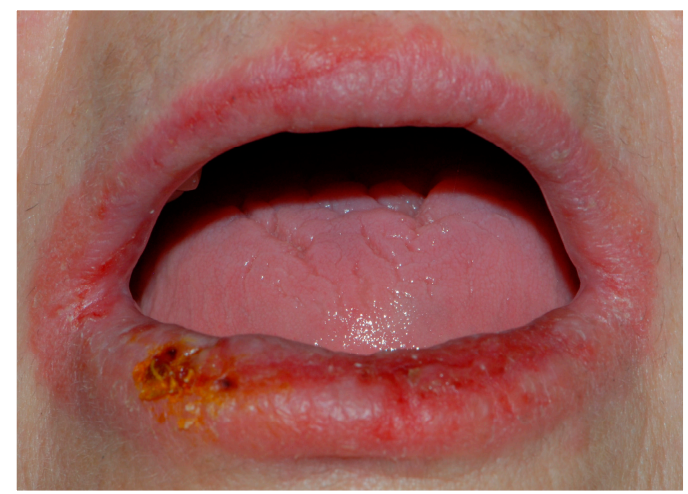

Figure 1. Contact cheilitis.

Post-radio and/or-chemotherapy cheilitis is a lips localization of oral mucositis that may occur in $30-60 \%$ of patients receveing radiotherapy for head-neck cancer, $90 \%$ of patients receiving concomitant chemoteraphy and in $75 \%$ of patients receveing high-dose of myeloablative drugs used for conditioning regimens for allogenic hematopoietic stemcell transplantation. The lesion undergo spontaneous resolution.

Actinic cheilitis (Figure 2) is due to prolonged sun exposure and occurs almost exclusively in fair-skinned people who work outdoors or spend too much time in the sun. It occurs more frequently on the lower lip, probably because the site is more directly exposed to sunlight. Clinical aspects consist in painless whitish discolorations at the border of the lips and the skin. The lips may gradually become scaly and indurated and chronic focal ulcerations can occur. Actinic cheilitis is a potential malignant disorder: the malignant transformation ranges from $10 \%$ to $30 \%$ [4]. Smoking might produce a synergistic effect. Follow-up is recommended with the execution of incisional biopsies in lesions with more severe clinical aspects. Surgery treatment options include cryosurgery, electrosurgery, laser vaporization and scalpel vermilionectomy. In a systematic review conducted by Vasconcelos Carvalho et al. remission rate and recurrence rate of actinic cheilitis were higher and lower respectively for surgical treatment compared to non surgical treatment [6]. 


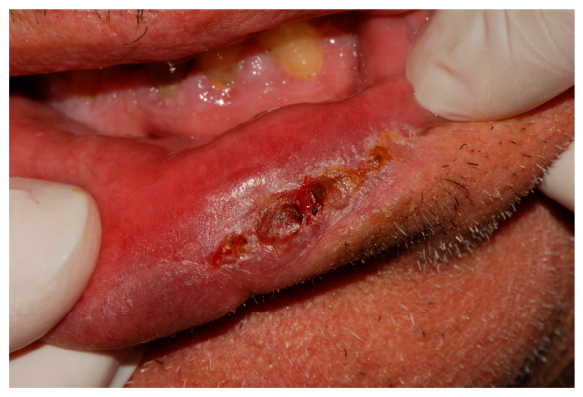

Figure 2. Actinic cheilitis.

Cheilitis granulomatosa (of Miescher) is a rare, painless and idiophatic swelling of the lip belonging to the larger group of orofacial granulomatosis caused by non-caseating granulomatous inflammation. When accompanied by facial palsy and plicated tongue, it is referred as MelkerssonRosenthal syndrome. The association between cheilitis granulomatosa and Crohn's disease has been documented widely in the literature: sometimes cheilitis granulomatosa may precede Crohn's disease by up to several years. Therapy may include topical, intralesional and systemic corticosteroids/antibiotics and surgery in severely disfiguring cases [7].

Plasmacellular cheilitis is a rare entities and manifests tipically on the lower lip with a circumscribed erosive and erithematous plaques or patches accompanied by pricking. The etiology is unknow and histologically is characterized by dense plasmacells infiltration in dermis. The clinical examination frequently leads to an initial misdiagnosis, which requires biopsy. Treatment include intralesional or systemic steroid and local application of immunomodulatory agents (e.g., tacrolimus, pimecrolimus) [8].

With the term cheilitis associated with systemic diseases refers to the lip manifestations of diseases such lupus erythematosus, oral lichen planus, pemphigus, pemphigoid, erytema multiforme, etc. We would like to suggest the introduction in this category of peri-oral psoriasis. Clinicians must pay attentions because sometimes lip lesions are the first manifestation of psoriasis, without skin involvement [9].

Angioedema results from vascular leakage due to release of vasoactive mediators such as histamine, serotonin, and bradykinin with extravasations of fluid into the superficial tissues causing edema. It can be classified as allergic, pseudo-allergic, or non-allergic atopic eczema.

Knowledge gaps amongst clinicians about different forms of cheilitis may influence the misdiagnosis and the mismanagement. Complete medical history, physical examination, appropriate diagnostic workup and interdisciplinary collaboration are the key factors in recognizing the right type of cheilitis and of its successful treatment. A small number of lip lesions, however, are potentially lethal and thus require appropriate intervention to prevent further morbidity and mortality.

Funding: No funding has been received in support of this paper.

Conflicts of Interest: The authors declare no conflict of interest.

\section{References}

1. Collet, E.; Jeudy, G.; Dalac, S. Cheilitis, perioraldermatitis and contactallergy. Eur. J. Dermatol. 2013, 23, 303-307.

2. Lugović-Mihić, L.; Pilipović, K.; Crnarić, I.; Šitum, M.; Duvančić, T. Differential Diagnosis of CheilitisHow to Classify Cheilitis? Acta Clin. Croat. 2018, 57, 342-351

3. Bakula, A.; Lugović-Mihić, L.; Šitum, M.; Turčin, J.; Šinković, A. Contact allergy in the mouth: diversity of clinical presentations and diagnosis of common allergens relevant to dental practice. Acta Clin. Croat. 2011, 50, 553-561.

4. Mortazavi, H.; Baharvand, M.; Mehdipour, M. Oral Potentially Malignant Disorders: An Overview of More than 20 Entities. J. Dent. Res. Dent. Clin. Dent. Prospect. 2014, 8, 6. 
5. Minciullo, P.L.; Paolino, G.; Vacca, M.; Gangemi, S.; Nettis, E. Unmet diagnostic needs in contact oral mucosal allergies. Clin. Mol. Allergy 2016, 14, 10.

6. Carvalho, M.V.; de Moraes, S.L.D.; Lemos, C.A.A.; Santiago Júnior, J.F.; Vasconcelos, B.C.D.E.; Pellizzer, E.P. Surgical versus non-surgical treatment of actinic cheilitis: A systematic review and meta-analysis. Oral. Dis. 2019, 25, 972-981.

7. Critchlow, W.A.; Chang, D. Cheilitis granulomatosa: A review. Head Neck Pathol. 2014, 8, $209-213$.

8. Lee, J.Y.; Kim, K.H.; Hahm, J.E.; Ha, J.W.; Kwon, W.J.; Kim, C.W.; Kim, S.S. Plasma Cell Cheilitis: A Clinicopathological and Immunohistochemical Study of 13 Cases. Ann. Dermatol. 2017, 29, 536-542.

9. Martí, N.; Pinazo, I.; Revert, A.; Jordá, E. Psoriasis of the lips. J. Dermatol. Case Rep. 2009, 3, 50-52.

(C) 2019 by the authors. Licensee MDPI, Basel, Switzerland. This article is an open access article distributed under the terms and conditions of the Creative Commons Attribution (CC BY) license (http://creativecommons.org/licenses/by/4.0/). 